\title{
A Preliminary Retrospective and Prospective Cohort Study on a Traditional Chinese Long-term Extreme Fasting
}

Chao Wang ${ }^{1+}$, Ligang Ming ${ }^{2+}$, Lijun Jia ${ }^{3}$, Qi Wang ${ }^{4,5,6}$, Tingting Cao ${ }^{1}$, Liping Wang ${ }^{2}$, Zijing Zhou ${ }^{1}$, Dan Tong ${ }^{1}$, Wei Li ${ }^{5}$, Yiqing $\mathrm{Wu}^{1}$, Hong Ding ${ }^{7 *}$, Di Liư ${ }^{4 *}$ Minghui Zhang ${ }^{1^{*}}$

*These authors contributed equally to this work.

†These authors contributed equally to this work.

School of Medicine, Tsinghua University, Beijing, China (C Wang PhD, T Cao MSc, Z Zhou MSc, D Tong MSc, Y Wu MSc, Prof M Zhang MD); Cancer Institute of Longhua Hospital, Shanghai University of Traditional Chinese Medicine, Shanghai, China (L Jia PhD); Nanshan Branch of Qilu Hospital, Yantai, China (L Ming MD, L Wang MD); Institute of Microbiology, Chinese Academy of Sciences, Beijing, China (Q Wang BSc, Wei Li MSc, Prof D Liu PhD); Institute of Virology, Chinese Academy of Sciences, Wuhan, China (Q Wang BSc, Prof D Liu PhD); Institute of Physical Science and Information Technology, Anhui University, Hefei, China (Q Wang BSc); The 8th Medical Center of Chinese PLA General Hospital, Beijing, China (H Ding MD).

Correspondence to:

NOTE: This preprint reports new research that has not been certified by peer review and should not be used to guide clinical practice. 
medRxiv preprint doi: https://doi.org/10.1101/2020.03.14.20036111; this version posted March 18, 2020. The copyright holder for this preprint (which was not certified by peer review) is the author/funder, who has granted medRxiv a license to display the preprint in It is made available under a CC-BY-NC-ND 4.0 International license .

Prof Minghui Zhang, School of Medicine, Tsinghua University, Haidian District, Beijing 100084, China.

Email: immunolzhang@hotmail.com;

Tel: 86-10-62799520.

Prof Di Liu, Wuhan Institute of Virology, Chinese Academy of Sciences, Wuhan 430071, China.

Email: liud@wh.iov.cn;

Tel: $86-27-87198167$

Hong Ding, The 8th Medical Center of Chinese PLA General Hospital, Beijing 100094, China.

Email: 13911883299@163.com;

Tel: 86-10-13911883299

\section{Abstract}

Background Fasting has long been a ritual or practice in varied religions, and recently, has been noticed to reduce the risk factors of metabolic diseases. In China, varied populations performed a traditional Taoism fasting practice, which lasted for 21 -day with $<5 \%$ calorie intake. However, the safety and applicability of this procedure haven not been investigated. 
medRxiv preprint doi: $h t t p s: / / d o i . o r g / 10.1101 / 2020.03 .14 .20036111$; this version posted March 18, 2020. The copyright holder for this

Methods A total of 144 volunteered participants in six camps following the 21-day fasting (with $<5 \%$ of normal diet) were investigated. 124 were examined for physical biomarkers and 53 of which also had biochemical markers. Another open label, non-comparative, phase 1/2 prospective cohort study enrolling 20 participants with metabolic diseases was also performed. The physical indices and biochemical biomarkers were collected at varied point of the fasting procedure. Statistical comparison and metagenomic analysis were performed. This study was registered in ClinicalTrials.gov (NCT03193177).

Findings Our preliminary retrospective cohort study showed that no severe adverse event (grade 3 or above) was reported, and all biomarkers fluctuated within the safe ranges, except for the urea acid. The 21-day fasting could significantly reduce BMI and blood pressures. The prospective cohort study of the metabolic diseased participants showed a significant reduction of BMI (3.3 \pm 1.0$)$ and systolic blood pressure $(28.7 \pm 17.8 \mathrm{mmHg})$ after the fasting procedure. The data also presented significant ameliorations on overweight (16/16), hypertension (11/11) and fatty liver (9/9).

Interpretation The 21-day fasting appeared safe and feasible for both healthy and unhealthy people. It could ameliorate the risk factors associated with hypertension and hyperlipidemia.

Funding This work was supported by National Natural Science 
medRxiv preprint doi: https://doi.org/10.1101/2020.03.14.20036111; this version posted March 18, 2020. The copyright holder for this preprint (which was not certified by peer review) is the author/funder, who has granted medRxiv a license to display the preprint in It is made available under a CC-BY-NC-ND 4.0 International license.

Foundation of China and China Overseas-Educated Scholars Development Foundation.

\section{Keywords}

Fasting, metabolic disorder, hypertension, hyperlipidemia, fatty liver

\section{Research in context}

\section{Evidence before this study}

Fasting has long been a ritual or practice in varied religions. In modern science, it has been noticed that fasting or calorie-restricted diets could benefit for the prevention or treatment of metabolic disorder-associated diseases. In China, the fasting practice, called "Bigu" (literally: avoiding grains), is believed to be capable of prolonging life in Taoism and was also used for medical cure. Compared to the reported fasting practices, the Bigu regimen is a more restricted abstinence, in which the practicers usually experience a continuous 21-day practice with an extremely low-calorie intake ( $<5 \%$ of normal diet). In a rough estimation, there are dozens of Bigu practice camps and over ten thousand practicers per year in China. However, nearly all Bigu camps followed the traditional Taoist procedures but lacked medical and scientific evaluation, which made those practices either mysterious or superstitious to the public.

Added value of this study 
medRxiv preprint doi: https://doi.org/10.1101/2020.03.14.20036111; this version posted March 18, 2020. The copyright holder for this

Our data showed that no severe adverse event was reported during the 21-day fasting procedure, and all biomarkers fluctuated within the safe ranges, except for the urea acid. The 21-day fasting could significantly reduce $\mathrm{BMI}$ and blood pressures. The data also presented significant ameliorations on overweight, hypertension and fatty liver. This 21-day fasting appeared safe and feasible for both healthy and unhealthy people. It could ameliorate the risk factors associated with hypertension and hyperlipidemia.

\section{Implications of all the available evidence}

This preliminary cohort study showed that the long-term extreme fasting was safety to most people and exhibited promising therapeutic effects to hypertension, hyperlipidemia and fatty liver. However, a large cohort study of health-improving effects by long-term extreme fasting is needed.

\section{Introduction}

Fasting features abstinence or reduction of food, drink or both in a period of time, and is normally acted as ritual in many religions. Muslims incorporate periods of fasting into their rituals from dawn until dusk during the month of Ramadan; Hindus fast on certain days of a month; while some Christian denominations follow the acceptable fast according to Bible. In China, the fasting practice, called "Bigu" (literally: avoiding 
medRxiv preprint doi: https://doi.org/10.1101/2020.03.14.20036111; this version posted March 18, 2020. The copyright holder for this

grains), are believed to be capable of prolonging life in Taoism and was also used for medical cure. In modern science, it has been noticed that fasting or calorie-restricted diets could benefit for the prevention or treatment of cardiovascular diseases $(1,2)$, autoimmune diseases(3), cancers $(2,4)$, diabetes(5-7), and also proved their applicability in tumor suppression(8-11), life extension(12), neural repair(13) and autoimmune remission(14) in mice. Particularly, some clinical trials focusing on short time (less than 7 consecutive days, $36-56 \%$ of normal diet) fasting-mimicking $\operatorname{diet}(2,15)$ or prolonged low intensity (6 months, approximately $75 \%$ of normal diet) calorie restriction $\operatorname{diet}(1,6,7)$ have been carried out, and the safety and capability to improve health were well examined.

Compared to the above fasting practices (fasting-mimicking diet and calorie restriction diet), the Bigu regimen is a more restricted abstinence, in which the participants usually experience a continuous 21-day practice with an extremely low-calorie intake $(<5 \%$ of normal diet) under the supervision of Bigu Masters. In a rough estimation, there are dozens of Bigu practice camps and over ten thousand participants per year in China and become popular in both aging population and middle-aged high-income population. Of special note, nearly all Bigu camps followed the traditional Taoist procedures and lacked medical and scientific evaluation, which made those practices either mysterious or 
medRxiv preprint doi: https://doi.org/10.1101/2020.03.14.20036111; this version posted March 18, 2020. The copyright holder for this preprint (which was not certified by peer review) is the author/funder, who has granted medRxiv a license to display the preprint in It is made available under a CC-BY-NC-ND 4.0 International license .

superstitious to the public. Hence, whether the long-time extreme fasting process could result in safe and effective outcome requires scientific investigation.

In this study, we investigated 144 volunteer Bigu participants in six camps, which followed the 21-day regimen (with $<5 \%$ of normal diet). The first 124 volunteers were collected for physical biomarkers and 53 of which have both physical and biochemical markers during the entire procedure. The data showed that the biomarkers return to normal ranges in about 10 days post the end of fasting, and the participant showed no severe adverse effect. Interestingly, we noticed that some participants with cardiovascular diseases had the previous aberrant physical markers back to the healthy levels after the whole fasting procedure. Of special interest, we prospectively followed 20 participants with aberrant biomarkers of cardiovascular diseases, and tracked their physical indications at pre-fasting, fasting and post-fasting. The results showed that 16 participants with higher BMI, 11 with hypertension and 9 with fatty liver got a significant amelioration, indicative of its potential therapeutic effects. In general, this preliminary cohort study showed that the long-term extreme fasting was safe to both healthy and unhealthy people and exhibited promising therapeutic effects.

\section{Materials and Methods}


medRxiv preprint doi: $h t t p s: / / d o i . o r g / 10.1101 / 2020.03 .14 .20036111$; this version posted March 18, 2020. The copyright holder for this

\section{Long-term extreme fasting (Bigu regimen) Procedures}

All subjects receiving Bigu regimen should stay together for at least the first three days with the supervision by an expert. Exercises and meditation should be performed twice a day (usually once in the morning and once in the afternoon). The whole process of Bigu regimen was divided into two sections. For the first phase, participants should be maintained in a water-only or extremely low-calorie intake diet for 21 days under the instruction of an experienced supervisor. The source of calorie was mainly from brown sugar water and honey water ( 141.8kJ), each of which should be taken less than $1000 \mathrm{~mL}$ per day. Participants who suffered from severe starvation could have $4 \mathrm{~g}$ of dates, $3 \mathrm{~g}$ of peanuts and $2 \mathrm{~g}$ of walnuts $(\sim 138.1 \mathrm{~kJ})$. Comparison of macronutrient and micronutrient intake between this fasting procedure and normal diet was shown as Table 2. For the second phase, these participants resumed taking foods incrementally for the first seven days (from day 22 to day 28). A detailed recommended diet composition during the 7-day resuming period was listed as Table 3. Participants could not take normal diets until finishing the second phase in order to avoid accidental damage to the gastrointestinal tract.

\section{Patient cohorts}

This study (ClinicalTrials.gov; NCT03193177) contained three progressive sections (Table 1). We firstly took a basic survey on 124 people who 
medRxiv preprint doi: https://doi.org/10.1101/2020.03.14.20036111; this version posted March 18, 2020. The copyright holder for this preprint (which was not certified by peer review) is the author/funder, who has granted medRxiv a license to display the preprint in It is made available under a CC-BY-NC-ND 4.0 International license.

voluntarily performed the Bigu regimen for 21 days. Of these 124 subjects, 53 participants were completely followed before, during and after Bigu regimen when their weight, blood pressure and blood biochemistry biomarkers were examined. According to these survey results, we prospectively followed 20 participants with aberrant biomarkers of cardiovascular diseases, and tracked their physical indications at pre-fasting, fasting and post-fasting. This study was conducted in Nanshan Branch of Qilu Hospital from June to September in the year 2017 and 20 subjects were voluntarily enrolled into this observational study. Of these 20 participants, 18 had succeeded in accomplishing the entire period of fasting, 1 withdrew on day 8 because of scheduling conflicts and 1 withdrew on day 14 due to the noncompliance of Bigu regimen. All participants have signed voluntary informed consent for collection and analysis of blood and fecal microbiome samples under Institutional Review Board (IRB)-approved protocols (THUMED-BG-170612). All clinical examination and evaluation was carried out independently and recorded instantaneously.

\section{Statistical analysis}

After verify normally distribution of the data, comparison between two time points (e.g. day 0 versus day 21) was performed using paired two-tailed Student's $t$ tests. When the data does not follow normal distribution, comparison was carried out using Wilcoxon signed-rank test. 
medRxiv preprint doi: https://doi.org/10.1101/2020.03.14.20036111; this version posted March 18, 2020. The copyright holder for this preprint (which was not certified by peer review) is the author/funder, who has granted medRxiv a license to display the preprint in It is made available under a CC-BY-NC-ND 4.0 International license .

$P$ values $<0.05$ were considered significant. ${ }^{* * *}$ means $P<0.001, * *$ means $0.001<P<0.01$ and $*$ means $0.01<P<0.05$.

\section{Role of the funding source}

The funder of the study had no role in study design, data collection, data analysis, data interpretation, or writing of the report. The corresponding author had full access to all the data in the study and had final responsibility for the decision to submit for publication.

\section{Results}

\section{A basic survey of physical markers follows 124 bigu participants}

From March 2016 to Oct 2017, we followed 124 people who carried out 21-day Bigu regimen and recorded their physical markers just pre-fasting (day 0), mid-fasting (day 10), end-of-fasting (day 21) and 10-day post fasting (day 31) (Figure 1A). Of these 124 participants, 48 (39\%) were male and 76 (61\%) were female. During fasting, the participants were asked to report any physical discomfort in time. The most common self-reported grade 1 symptom is fatigue, while dry mouth, tingling and nausea were also listed. Weakness, vomiting, asthma and fever has been reported occasionally as the grade 2 symptoms. No severe adverse event was reported as grade 3 and above (Figure 1B). We investigated the normal activities of each participant by using a detector MI Band worn on the wrist, to record walking distance, heart rates, sleeping time and 
medRxiv preprint doi: $h t t p s: / / d o i . o r g / 10.1101 / 2020.03 .14 .20036111$; this version posted March 18, 2020. The copyright holder for this

consumed energy. The data presented no significant difference during fasting compared to those at day 0 (Figure $1 \mathrm{C}$ ), indicating those participants kept daily activities during the procedure. These data suggested that the long-term extreme (21-day, $<5 \%$ of normal diet) fasting procedure causes no adverse events beyond grade 2 and is likely be safe to most normal people.

\section{A detailed analysis on physical biomarkers of 53 participants}

We further reviewed the data of all 124 participants, 53 of which had serial physical indices. Among the 20 examined indices, the BMI, diastolic blood pressure and systolic blood pressure decreased significantly in participants during fasting, compared to day 0 (Figure 1D). Meanwhile, some metabolic biomarkers, including blood urea nitrogen (BUN), total cholesterol (TC), triglyceride (TG), low density lipoprotein (LDL), creatinine (CRE) and high density lipoprotein (HDL) also declined during this procedure (Figure 1D). No microelements fell below normal levels, though $\mathrm{Fe}, \mathrm{Ca}, \mathrm{Cl}$ and $\mathrm{P}$ showed slightly decreases (Figure 1D). Unexpectedly, the fasting glucose was not detected decrease on day 21 (end-of-fasting), ruling out hypoglycemia during this period (Figure 1D). These data indicated that the long-term extreme fasting did not cause severe deviations out of the normal ranges of those physical indices, though as expected, some biomarkers (e.g. uric acid, triglyceride) had a significant fluctuation. The results also presented that the fasting 
medRxiv preprint doi: $h t t p s: / / d o i . o r g / 10.1101 / 2020.03 .14 .20036111$; this version posted March 18, 2020. The copyright holder for this

procedure could decrease the blood pressure and blood cholesterol associated biomarkers, while kept blood glucose balanced, implying its potential therapeutic effects on hypertension and hyperlipidemia.

\section{A prospective study on 20 participants with hypertension or hyperlipidemia}

In order to examine whether this long-term extreme fasting would benefit those people with hypertension and/or hyperlipidemia, we prospectively recruited 20 unhealthy people (in one Bigu camp) and detected their dynamic changes of metabolic physical biomarkers, from June $18^{\text {th }}$ to Sep $8^{\text {th }}$ in the year 2017. Among the 20 participants, 7 (35\%) were male and 13 (65\%) were female. Eighteen of 20 participants had succeeded in accomplishing the entire period of fasting, 1 withdrew on day 8 because of scheduling conflicts and 1 withdrew on day 14 due to the noncompliance of Bigu regimen (Figure 2A). Of note, we kept collecting data from those 18 participants until day 51 (30-day post resuming). Before fasting (examined on day 0), 16 participants were overweight, 11 suffered from hypertension, 9 were hyperlipidemia, 3 were hyperglycemia, and 9 had fatty liver (Table 4).

We following carried out physical examination and biomarker detection on day 0 , day 4 , day 7 , day 14 , day 21 and day 51 (Figure $2 A$ ). The data showed that the 21-day fasting resulted in a significant reduction by 9.2 $\pm 3.2 \mathrm{~kg}(\mathrm{P}<0.001)$ of body weight, accordance with a reduction by 3.3 
medRxiv preprint doi: $h t t p s: / / d o i . o r g / 10.1101 / 2020.03 .14 .20036111$; this version posted March 18, 2020. The copyright holder for this

\pm 1.0 of BMI (Figure 2B). Systolic blood pressure was reduced by $28.7 \pm$ $17.8 \mathrm{mmHg}$, whereas diastolic blood pressure did not reach a significant change. Levels of three markers associated with hypertension including rennin, angiotensin I and angiotensin II were detected significant increases $(P<0.001$, Figure $2 C)$, indicating a feedback to elevate blood pressure through the rennin-angiotensin system. We also found that both total body lean and total body fat were significantly decreased during fasting process (Figure 2B), indicating the consumption of both muscles and fats for energy production.

Since most of the participants recruited suffered from metabolic diseases, we followed their metabolism associated biomarkers during the fasting procedure (Figure 2D). In the whole period, the concentrations of $\mathrm{Na}, \mathrm{Cl}$, $\mathrm{P}, \mathrm{K}$ and $\mathrm{Ca}$ were not found to deviate beyond their normal ranges, while they still experienced fluctuations. The data showed that the levels of alanine transaminase, aspartate transaminase, total bilirubin, indirect bilirubin, direct bilirubin, ferritin, lactate dehydrogenase and creatine kinase were increased significantly. As glucose metabolic pathway was inhibited due to the lack of carbohydrate intake, levels of total cholesterol and low density lipoprotein, as well as total protein were elevated transiently during this period, but the level of high density lipoprotein was found to be decreased. The level of uric acid was found to be significantly increased after starting fasting, which did not return to 
medRxiv preprint doi: https://doi.org/10.1101/2020.03.14.20036111; this version posted March 18, 2020. The copyright holder for this

the normal level until resuming normal diet (Figure 2D). The glucose level was decreased during the first seven days of fasting, while it started to increase on day 14, which was beyond our expectations. However, the insulin level started to decrease just after starting fasting and remained the lower level during the whole procedure.

As hormone plays an important role in regulating physical activities, dynamics of the levels of thyroid hormones and sex hormones were recorded at indicated time points (Figure 2E). For thyroid hormones, both TSH and serum free T3 levels were decreased significantly during fasting, the level of T4 was increased transiently on day 14, but ATG level did not show an obvious change. But among sex hormones including luteinizing hormone, follicle-stimulating hormone, prolactin, estradiol, progesterone and testosterone, only the levels of follicle-stimulating hormone and luteinizing hormone in women significantly increased during fasting procedure and maintained at the higher levels even on day 51.

Then we evaluate the effects of the 21-day fasting on metabolic diseases by assessing the changes of biomarkers and imaging examinations (Table 5). We examined the indices of all participants on day 21 . The data showed that among the 12 participants with higher BMI (>23.9), 6 were reduced to the normal range, and the other 6 had a significant decrease $(\mathrm{P}<0.001)$. Of 11 participants suffering from hypertension, 9 decreased to 
medRxiv preprint doi: https://doi.org/10.1101/2020.03.14.20036111; this version posted March 18, 2020. The copyright holder for this

the normal range, and the remaining 2 also had a remarkable decrease. Besides, the long-time extreme fasting were proved to be effective on fatty liver. We found that in 9 participants with fatty liver, 7 were ameliorated, including 2 from severe to moderate or mild, 4 from moderate to mild, and 1 from mild to non-fatty liver (Figure S1A-I). Conclusively, these data suggested that bigu regimen could benefit the unhealthy people in the high BMI, hypertension and fatty liver.

\section{Post hoc analysis of health-threatening factors}

As abnormal levels of biomarkers leading to increased risk factors of metabolic diseases, we selected clinically relevant cutoffs and compared normal and at-risk subjects for each risk factor (Figure 3), where systolic blood pressure $>140 \mathrm{mmHg}$ or diastolic blood pressure $>90 \mathrm{mmHg}$ are associated with hypertension, total cholesterol $>6 \mathrm{mmol} / \mathrm{L}$ and LDL $>3.3 \mathrm{mmol} / \mathrm{L}$ are associated with hyperlipidemia and fasting glucose $>6.1 \mathrm{mmol} / \mathrm{L}$ is associated with hyperglycemia. The data showed that subjects with a systolic blood pressure $>140 \mathrm{mmHg}$ experienced a greater reduction by $18.6 \pm 10.7 \mathrm{mmHg}$ in systolic blood pressure than those with normal systolic blood pressure by $3.4 \pm 12.4 \mathrm{mmHg}(P=0.039)$. However, comparison between participants with diastolic blood pressure $>90 \mathrm{mmHg}$ and those with normal diastolic blood pressure did not show any difference. Total cholesterol was reduced significantly in participants with baseline levels above $6 \mathrm{mmol} / \mathrm{L}$ by $1.3 \pm 2.1 \mathrm{mmol} / \mathrm{L}$, 
medRxiv preprint doi: $h t t p s: / / d o i . o r g / 10.1101 / 2020.03 .14 .20036111$; this version posted March 18, 2020. The copyright holder for this

while it was slightly elevated in participants with normal baseline levels by $0.76 \pm 0.99 \mathrm{mmol} / \mathrm{L}(\mathrm{P}=0.01$ between groups). LDL was reduced by $0.34 \pm 0.68 \mathrm{mmol} / \mathrm{L}$ in those with $\mathrm{LDL}>3.3 \mathrm{mmol} / \mathrm{L}$ but was not reduced in normal-range participants ( $\mathrm{P}=0.016$ between groups). Besides, $\mathrm{BMI}$ changes between groups with normal range and overweight did not show significant difference $(P=0.281)$. These data indicated that the 21-day fasting had more pronounced effects in subjects with aberrant levels of these health-threatening factors than in subjects with normal levels of these physical indices.

\section{Typical case reports}

Case \#17 was the oldest man among these participants (Table 5). He was a 79 years old and was diagnosed with severe fatty liver just before starting fasting. Then he performed the 21-day fasting with a complete caloric deprivation without any major inconvenience and lost 7.1 kilogram (from $80.6 \mathrm{~kg}$ to $73.5 \mathrm{~kg}$ ). Levels of his blood pressure, total cholesterol and low-density lipoprotein did not change notably (Figure $4 A)$, while the extent of his fatty liver had a great improvement from severe fatty liver to mild fatty liver on day 51 (Table 5, Figure S1F). Notably, he had not received any treatment for his fatty liver from day 0 to day 51 after starting fasting.

Case \#4 was a 60-year-old Chinese women diagnosed with hypertension 
medRxiv preprint doi: $h t t p s: / / d o i . o r g / 10.1101 / 2020.03 .14 .20036111$; this version posted March 18, 2020. The copyright holder for this

and mild-moderate fatty liver (Table 5, Figure S1A). Her BMI was 29.6, much higher than the upper limit value 23.9. Different from other participants, she suffered from varied adverse effects during fasting, including fatigue, weakness, muscle pain, vomiting, headache and sometimes sleep disorder. Her systolic blood pressure also transiently raised from $141 \mathrm{mmHg}$ (day 0 ) to $166 \mathrm{mmHg}$ on day 4 , but then started to decline and reached to $116 \mathrm{mmHg}$ at the end of 21-day fasting (Figure 4B). Her hyperlipemia-associated biomarkers did not change significantly after fasting, though transient increases occurred on day 4 , day 7 and day 14 (Figure 4B). After fasting, the extent of her fatty liver turned better from mild-moderate on day 0 to mild on day 51 (Table 5, Figure S1A) through B-sonic without any other treatment.

Case \#10 was a 21-year-old Chinese man diagnosed with severe fatty liver, hypertension and overweight. His BMI was 44.3, the highest among all the participants, and his systolic blood pressure was $159 \mathrm{mmHg}$. He also experienced fatigue, weakness, nausea and vomiting occasionally during fasting. However, his BMI was decreased to 38.7 on day 21 and 39.3 on day 51 ; and his systolic blood pressure declined to $118 \mathrm{mmHg}$ on day 21 and raised to $141 \mathrm{mmHg}$ on day 51 (Figure 4C). Meanwhile, the extent of his fatty liver improved from severe on day 0 to moderate on day 51 (Table 5, Figure S1C) without any other treatment. 
medRxiv preprint doi: https://doi.org/10.1101/2020.03.14.20036111; this version posted March 18, 2020. The copyright holder for this preprint (which was not certified by peer review) is the author/funder, who has granted medRxiv a license to display the preprint in It is made available under a CC-BY-NC-ND 4.0 International license .

Case \#1 was a 75-year-old Chinese woman diagnosed with hypertension. Before fasting, her BMI was 26.0 and her systolic blood pressure was $162 \mathrm{mmHg}$. After fasting, her BMI was decreased to 22.5 on day 21 and 23.2 on day 51 , while her systolic blood pressure declined to $138 \mathrm{mmHg}$ on day 21 and 204 on day 51 (Figure 4D). To our biggest surprise, she could still make her stools every 2-3 days even during fasting procedure.

\section{Discussion}

Fasting with different intensities has been performed for a long time out of cultural, religious and medical reasons(16). Accumulating evidences show that both calorie restriction and intermittent fasting are effective approaches to minimizing health-threatening factors, ameliorating detrimental inflammations, promoting antitumor therapies as well as extending lifespans $(2,17)$. Recent studies also showed that fasting could modulate immune system by affecting the numbers and functions of monocytes(18), B cells(19) and T cells(20), implicating a therapeutic potential for fasting to treat immune-related diseases(21). However, few clinical investigations on the effects of long-term ( $>7$ days) fasting have been conducted due to either the poor subject compliance or lack of systemic scientific observation and records. In this study, a well-organized Bigu camp with participants of good obedience has been 
followed in a timely and scientifically way, by which time serial dynamic changes of their physical indices could be recorded.

From our preliminary investigation, we found that at the 21-day fasting with $<5 \%$ calorie intake was applicable for normal people. No severe adverse effects greater than grade 2 were reported. Physical examination data also suggested that nearly all biological markers fell within the safe limits during fasting, except for the uric acid, which appeared beyond the normal range for nearly all particants. This should be caused by inhibition of renal excretion of uric acid by the ketosis of fasting(22). During the whole fasting procedure, either hypoglycemia or hyponatremia or hypokalemia has not been observed. Therefore, it is presented that the long-term extreme fasting following Bigu regimen seemed very likely to be safe for both healthy and un-healthy people.

Our data also showed that this long-time extreme fasting could help reduce health-threatening factors for participants with hypertension and hyperlipidemia. The data suggested that after fasting, the levels of BMI, diastolic blood pressure, systolic blood pressure, blood urea nitrogen, total cholesterol, low density lipoprotein and triglyceride were significantly decreased among all the participants. Compared to the previously reported clinical trials using fasting-mimicking diet(2), which presented significant decreases of the levels of BMI, diastolic blood pressure and systolic blood pressure, and decrease but not significant of 
medRxiv preprint doi: https://doi.org/10.1101/2020.03.14.20036111; this version posted March 18, 2020. The copyright holder for this

the levels of total cholesterol, low density protein and triglyceride, our data showed all markers were significantly decreased. Moreover, all the above indices showed excessive reductions following our fasting procedure than in the reported clinical trials. Since the long-term extreme fasting could result in more drastic decreases of cardiovascular associated biomarkers, it would lead to a better improvement of health.

Nonalcoholic fatty liver disease (NAFLD) is one of the most common liver diseases in parallel with obesity and other metabolic diseases (23, 24). It is driven by an access accumulation of metabolic substrates, e.g. fatty $\operatorname{acid}(25,26)$, and is considered to be a high risk factor of hepatocellular carcinoma(27). However, its therapeutic approaches are still limited, except for changing of life styles, especially diet $(23,28)$. Scientists found that the Mediterranean diet, with less intake of fatty acid, demonstrated to be of high benefit for NAFLD patients(29). In our study, a 21-day extreme fasting period could help minimize the intake of fatty acid but keep normal activities. More importantly, of the 9 participants with fatty liver, 7 were ameliorated, including 2 from severe to moderate or mild, 4 from moderate to mild, and 1 from mild to non-fatty liver (Figure S1A-I). These data suggested that long-time extreme fasting could be exploited as a safe and effective therapeutic approach for NAFLD patients.

In summary, we investigated the traditional Chinese long-time 
extreme fasting (Bigu regimen) using the evaluation system of modern medical sciences for the first time. The long-term extreme fasting appeared not only safe and feasible for both healthy and unhealthy people, but also could ameliorate the risk factors associated with hypertension and hyperlipidemia. Our study encouraged the further investigations on fasting and its therapeutic effects.

\section{Acknowledgments}

We thank Mr. Feng Liu, Mingjun Han and Yuanlei Chen for their help in the organization of this clinical trial and Beijing Tianyi Medical Technology Limited Company for their help in sample collection.

\section{Funding Sources:}

The study was supported by National Natural Science Foundation of China (numbers 81571532,81771687 and 81601429 ). MZ was supported by the China Overseas-Educated Scholars Development Foundation. DL was supported by the National Program for Support of Top-notch Young Professionals.

\section{Declaration of Interest}

We declare that we have no conflicts of interest. 


\section{Author Contributors}

$M Z, D L, H D, C W$ and $L M$ designed the study. CW, LM, QW, TC, LW, ZZ, DT,

WL and YW analysed the data. CW, LM, LJ, QW, TC, LW, HD, DL and MZ interpreted the data. CW, LM, QW, TC and DL prepared the figures. CW, QW, DL and $M Z$ wrote the paper. All authors approved the final manuscript as submitted and agree to be accountable for all aspects of the work.

\section{References}

1. M. N. Harvie et al., The effects of intermittent or continuous energy restriction on weight loss and metabolic disease risk markers: a randomized trial in young overweight women. Int J Obes (Lond) 35, 714-727 (2011).

2. M. Wei et al., Fasting-mimicking diet and markers/risk factors for aging, diabetes, cancer, and cardiovascular disease. Sci Transl Med 9, (2017).

3. H. Muller, F. W. de Toledo, K. L. Resch, Fasting followed by vegetarian diet in patients with rheumatoid arthritis: a systematic review. Scand J Rheumatol 30, 1-10 (2001).

4. Z. Lu et al., Fasting selectively blocks development of acute lymphoblastic leukemia via leptin-receptor upregulation. Nat Med 23, 79-90 (2017).

5. C. W. Cheng et al., Fasting-Mimicking Diet Promotes Ngn3-Driven beta-Cell Regeneration to Reverse Diabetes. Cell 168, 775-788 e712 (2017).

6. D. Florakis et al., Effect of hypocaloric diet plus sibutramine treatment on hormonal and metabolic features in overweight and obese women with polycystic ovary syndrome: a randomized, 24-week study. Int J Obes (Lond) 32, 692-699 (2008).

7. M. Harvie et al., The effect of intermittent energy and carbohydrate restriction v. daily energy restriction on weight loss and metabolic disease risk markers in overweight women. Br J Nutr 110, 1534-1547 (2013).

8. S. E. Dunn et al., Dietary restriction reduces insulin-like growth factor I levels, which modulates apoptosis, cell proliferation, and tumor progression in p53-deficient mice. Cancer Res 57, 4667-4672 (1997).

9. S. Brandhorst, M. Wei, S. Hwang, T. E. Morgan, V. D. Longo, Short-term calorie and protein restriction provide partial protection from chemotoxicity but do not delay glioma progression. Exp Gerontol 48, 1120-1128 (2013).

10. C. Lee et al., Fasting cycles retard growth of tumors and sensitize a range of cancer cell types to chemotherapy. Sci Transl Med 4, 124ra127 (2012).

11. S. Di Biase et al., Fasting-Mimicking Diet Reduces HO-1 to Promote T Cell-Mediated Tumor 
medRxiv preprint doi: https://doi.org/10.1101/2020.03.14.20036111; this version posted March 18, 2020. The copyright holder for this preprint (which was not certified by peer review) is the author/funder, who has granted medRxiv a license to display the preprint in It is made available under a CC-BY-NC-ND 4.0 International license.

Cytotoxicity. Cancer Cell 30, 136-146 (2016).

12. S. Brandhorst et al., A Periodic Diet that Mimics Fasting Promotes Multi-System Regeneration, Enhanced Cognitive Performance, and Healthspan. Cell Metab 22, 86-99 (2015).

13. A. J. Bruce-Keller, G. Umberger, R. McFall, M. P. Mattson, Food restriction reduces brain damage and improves behavioral outcome following excitotoxic and metabolic insults. Ann Neurol 45, 8-15 (1999).

14. I. Y. Choi et al., A Diet Mimicking Fasting Promotes Regeneration and Reduces Autoimmunity and Multiple Sclerosis Symptoms. Cell Rep 15, 2136-2146 (2016).

15. M. E. Levine et al., Low protein intake is associated with a major reduction in IGF-1, cancer, and overall mortality in the 65 and younger but not older population. Cell Metab 19, 407-417 (2014).

16. V. D. Longo, M. P. Mattson, Fasting: molecular mechanisms and clinical applications. Cell Metab 19, 181-192 (2014).

17. F. Pietrocola et al., Caloric Restriction Mimetics Enhance Anticancer Immunosurveillance. Cancer Cell 30, 147-160 (2016).

18. S. Jordan et al., Dietary Intake Regulates the Circulating Inflammatory Monocyte Pool. Cell 178, 1102-1114 e1117 (2019).

19. M. Nagai et al., Fasting-Refeeding Impacts Immune Cell Dynamics and Mucosal Immune Responses. Cell 178, 1072-1087 e1014 (2019).

20. N. Collins et al., The Bone Marrow Protects and Optimizes Immunological Memory during Dietary Restriction. Cell 178, 1088-1101 e1015 (2019).

21. R. Buono, V. D. Longo, When Fasting Gets Tough, the Tough Immune Cells Get Going-or Die. Cell 178, 1038-1040 (2019).

22. P. N. Cheifetz, Uric acid excretion and ketosis in fasting. Metabolism 14, 1267-1272 (1965).

23. B. A. Neuschwander-Tetri, Non-alcoholic fatty liver disease. BMC Med 15, 45 (2017).

24. H. Kitade, G. Chen, Y. Ni, T. Ota, Nonalcoholic Fatty Liver Disease and Insulin Resistance: New Insights and Potential New Treatments. Nutrients 9, (2017).

25. M. E. Ertunc, G. S. Hotamisligil, Lipid signaling and lipotoxicity in metaflammation: indications for metabolic disease pathogenesis and treatment. J Lipid Res 57, 2099-2114 (2016).

26. M. V. Machado, A. M. Diehl, Pathogenesis of Nonalcoholic Steatohepatitis. Gastroenterology 150, 1769-1777 (2016).

27. H. L. Reeves, M. Y. Zaki, C. P. Day, Hepatocellular Carcinoma in Obesity, Type 2 Diabetes, and NAFLD. Dig Dis Sci 61, 1234-1245 (2016).

28. A. J. Sanyal et al., Challenges and opportunities in drug and biomarker development for nonalcoholic steatohepatitis: findings and recommendations from an American Association for the Study of Liver Diseases-U.S. Food and Drug Administration Joint Workshop. Hepatology 61, 1392-1405 (2015).

29. L. European Association for the Study of the, D. European Association for the Study of, $O$. European Association for the Study of, EASL-EASD-EASO Clinical Practice Guidelines for the management of non-alcoholic fatty liver disease. J Hepatol 64, 1388-1402 (2016).

\section{Figure Legend}


medRxiv preprint doi: https://doi.org/10.1101/2020.03.14.20036111; this version posted March 18, 2020. The copyright holder for this

Figure 1. A preliminary survey of physical biomarkers in 53 subjects during 21-day fasting procedure. A. Schema of fasting procedure in this survey. B. Self-reported adverse effects were recorded according to CTCAE, where $0=$ No symptoms, $1=$ Mild, $2=$ Moderate, $3=$ Severe, $4=$ Life threatening, 5=Death. C. Daily activities were recorded using Mi Band. D. Basic physical biomarkers were examined during the entire fasting procedure.

Figure 2. A deep investigation of physical biomarkers in $\mathbf{2 0}$ subjects with metabolic diseases. A. Schema of fasting procedure in the clinical trial. B-E. Changes of non-invasive physical indexes (B), hypertension associated biomarkers (C), biochemical biomarkers (D) and hormone levels (E) were evaluated during the fasting procedure.

Figure 3. Post hoc analysis of physical biomarkers among subgroups classified by levels of aging/disease risk factors. All the 20 participants were classified into two or three subgroups by the severity of aging/disease risk factors. The $\Delta$ value represents a comparison to the baseline. $\mathrm{P}$ values were indicated between different subgroups at the same time points.

Figure 4. Dynamics of the levels of physical biomarkers for specific 
medRxiv preprint doi: https://doi.org/10.1101/2020.03.14.20036111; this version posted March 18, 2020. The copyright holder for this preprint (which was not certified by peer review) is the author/funder, who has granted medRxiv a license to display the preprint in It is made available under a CC-BY-NC-ND 4.0 International license .

cases. The data were examined at indicated time points. Dash areas show the normal ranges. 
Diet Pre-fasting Fasting

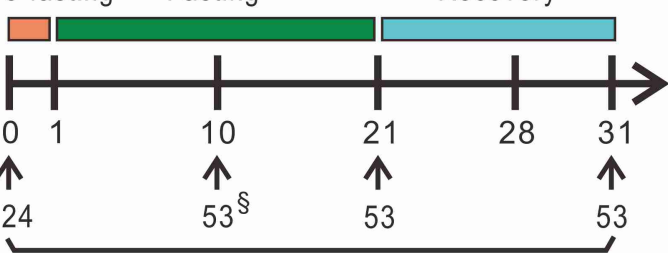

WT \& $\mathrm{BP}^{\ddagger}$ measurement

Blood routine analysis

Blood biochemistry evaluation

$\S_{71}$ participants withdraw because of 50 schedule confliction and 21 out of contact.

${ }^{*}$ WT stands for weight and BP is short for blood pressure.
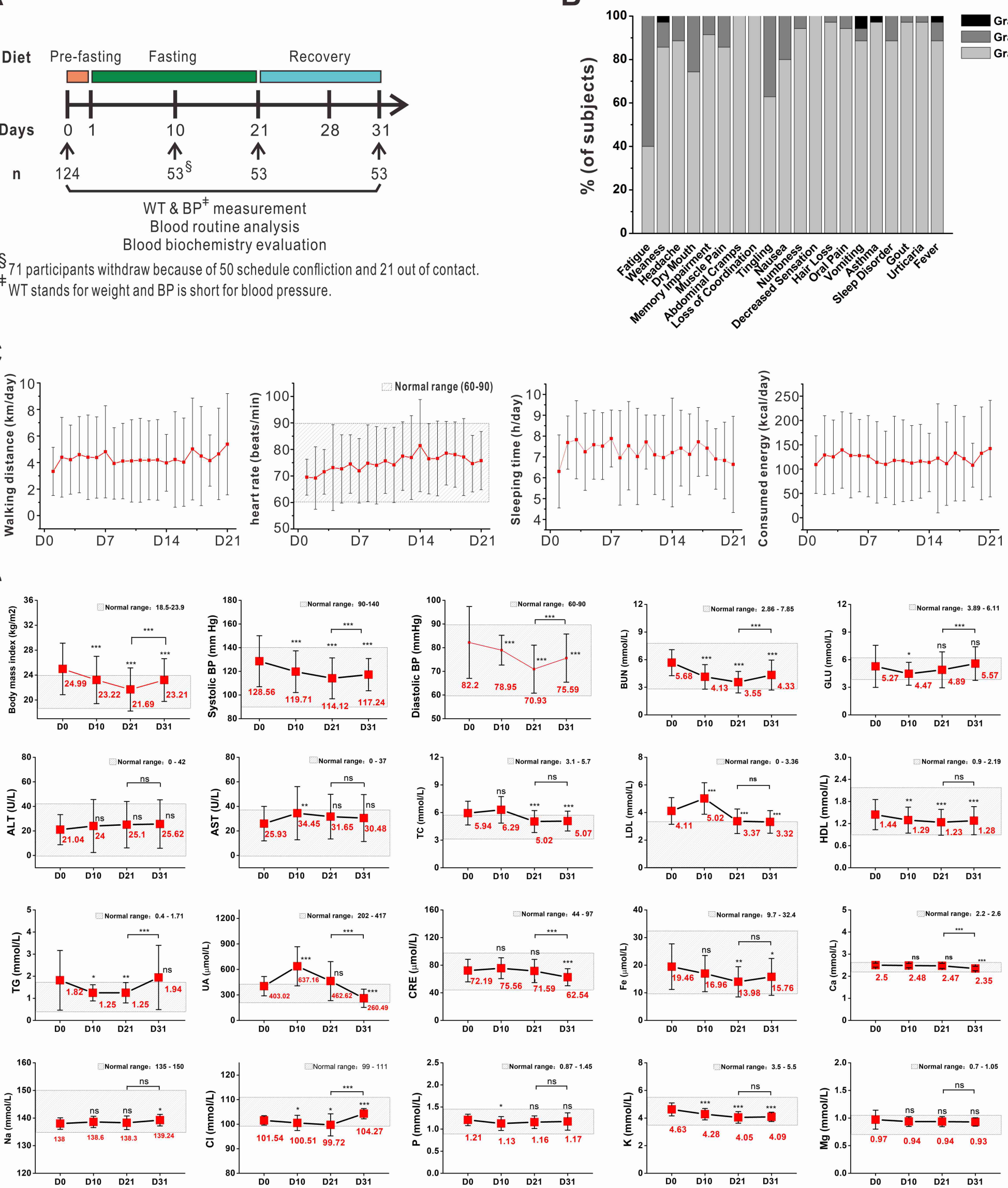

Fig.1. A more detailed survey of physical biomarkers in 53 subjects during fasting procedure. A. Schema of fasting procedure in this survey. B. Self reported adverse effects were recorded according to CTCAE, where $0=$ No symptoms, 1=Mild, 2=Moderate, 3=Severe, 4=Life threatening, 5=Death. C. Daily activities were recorded using Mi Band. D. Basic physical biomarkers were examined during the whole fasting procedure. 
Diet Pre-fasting

Recovery

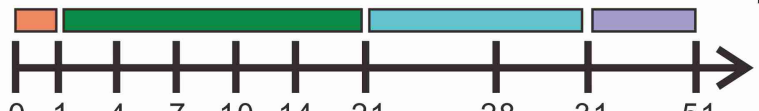

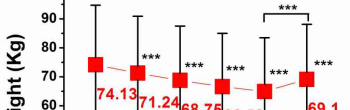

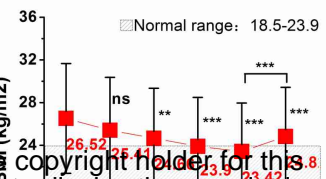

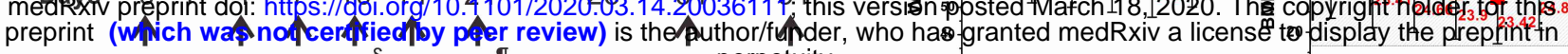

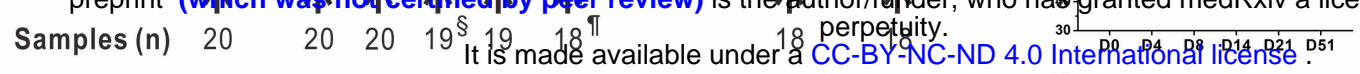

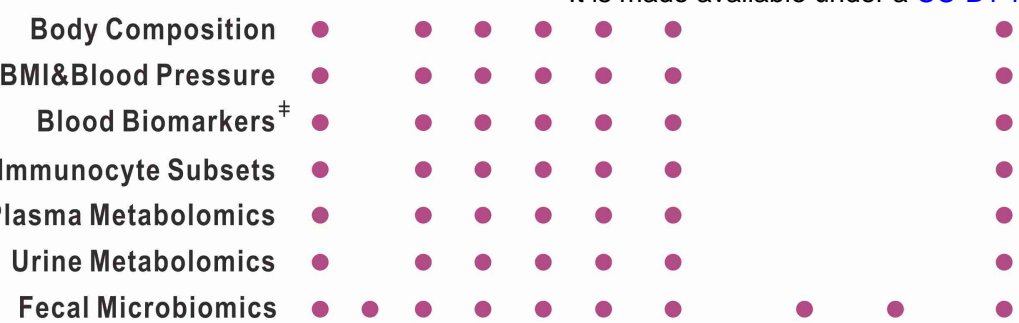

$\S 1$ participants withdraw because of scheduling conflicts.

I 1 participants withdraw because of noncompliance of bigu regimen.

Blood Biomarkers included metabolites, microelements and hormones.
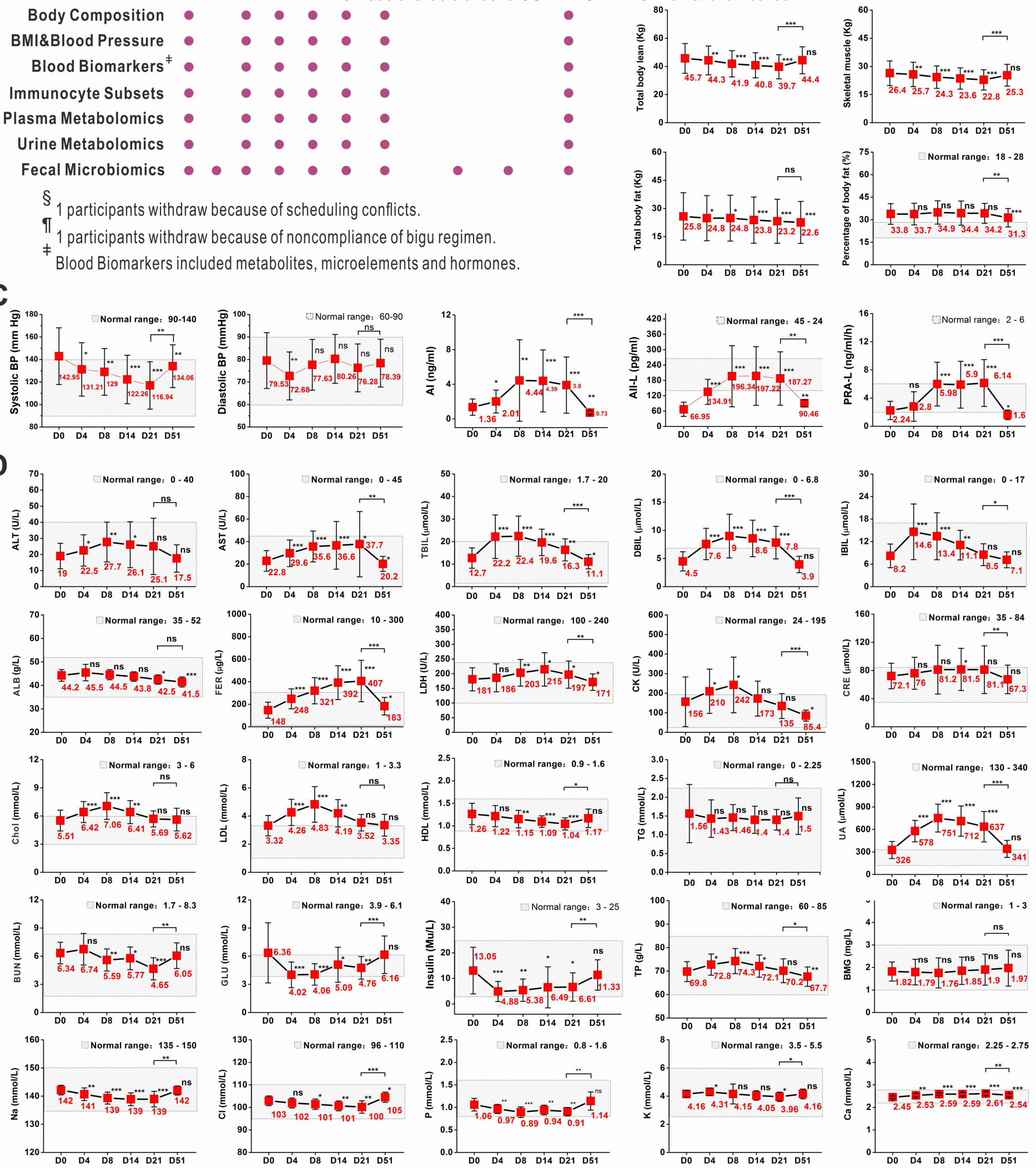

E
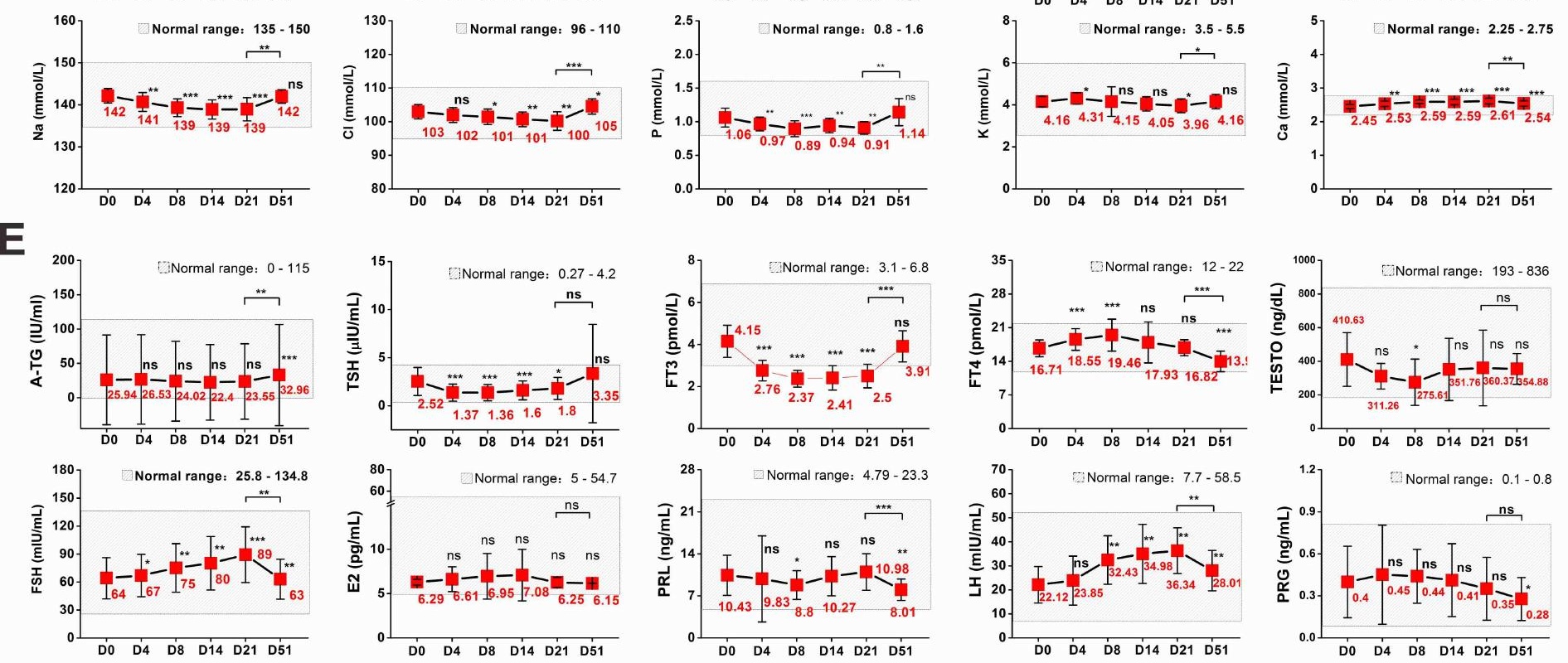

Fig.2. A deep investigation of physical biomarkers in 20 subjects with metabolic diseases. A. Schema of fasting procedure in the clinical trial. Changes of non-invasive physical indexes (B), hypertension associated biomarkers $(C)$, biochemical biomarkers $(D)$ and hormone levels $(E)$ were evaluated during the fasting procedure. 

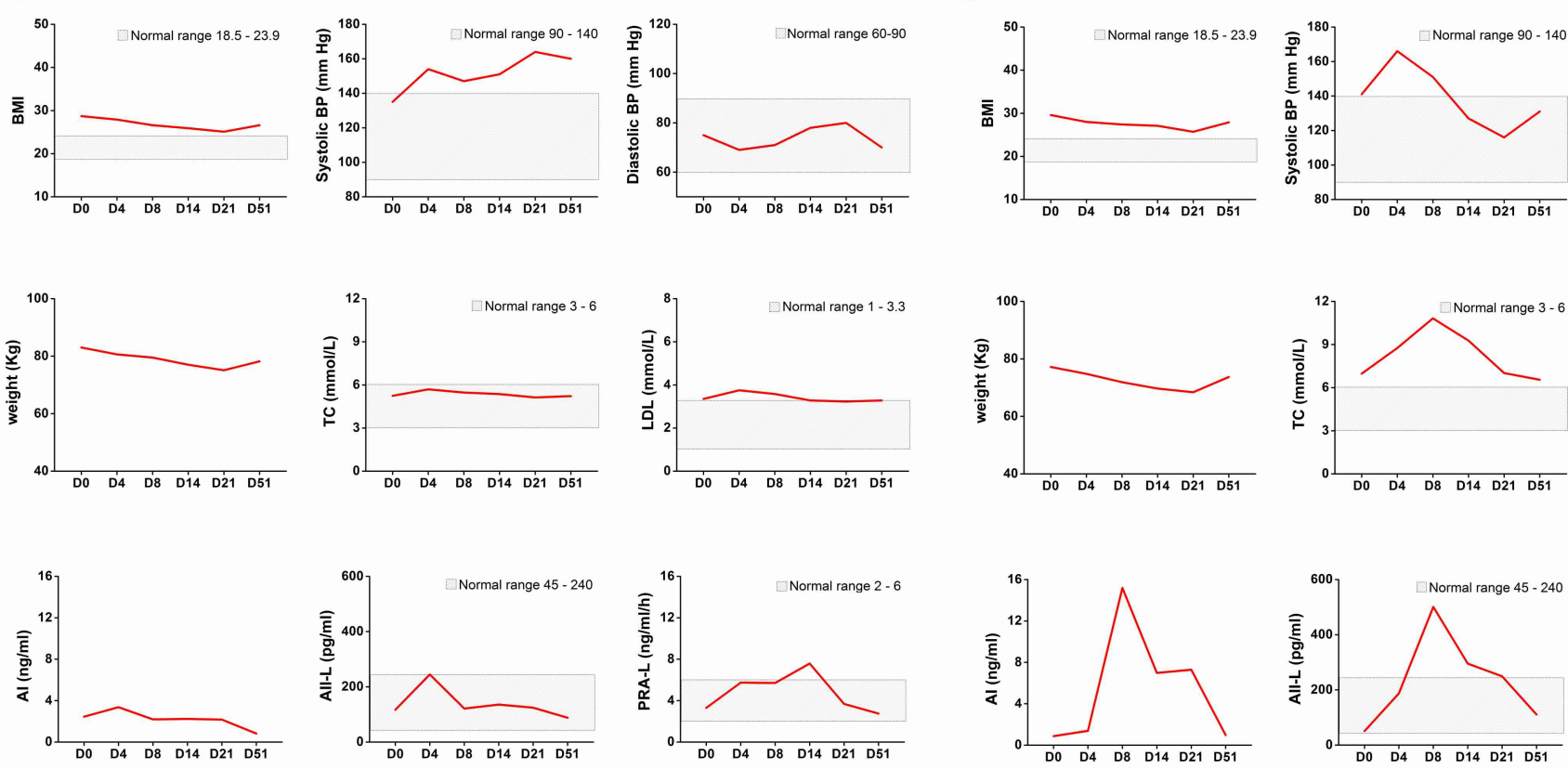

D
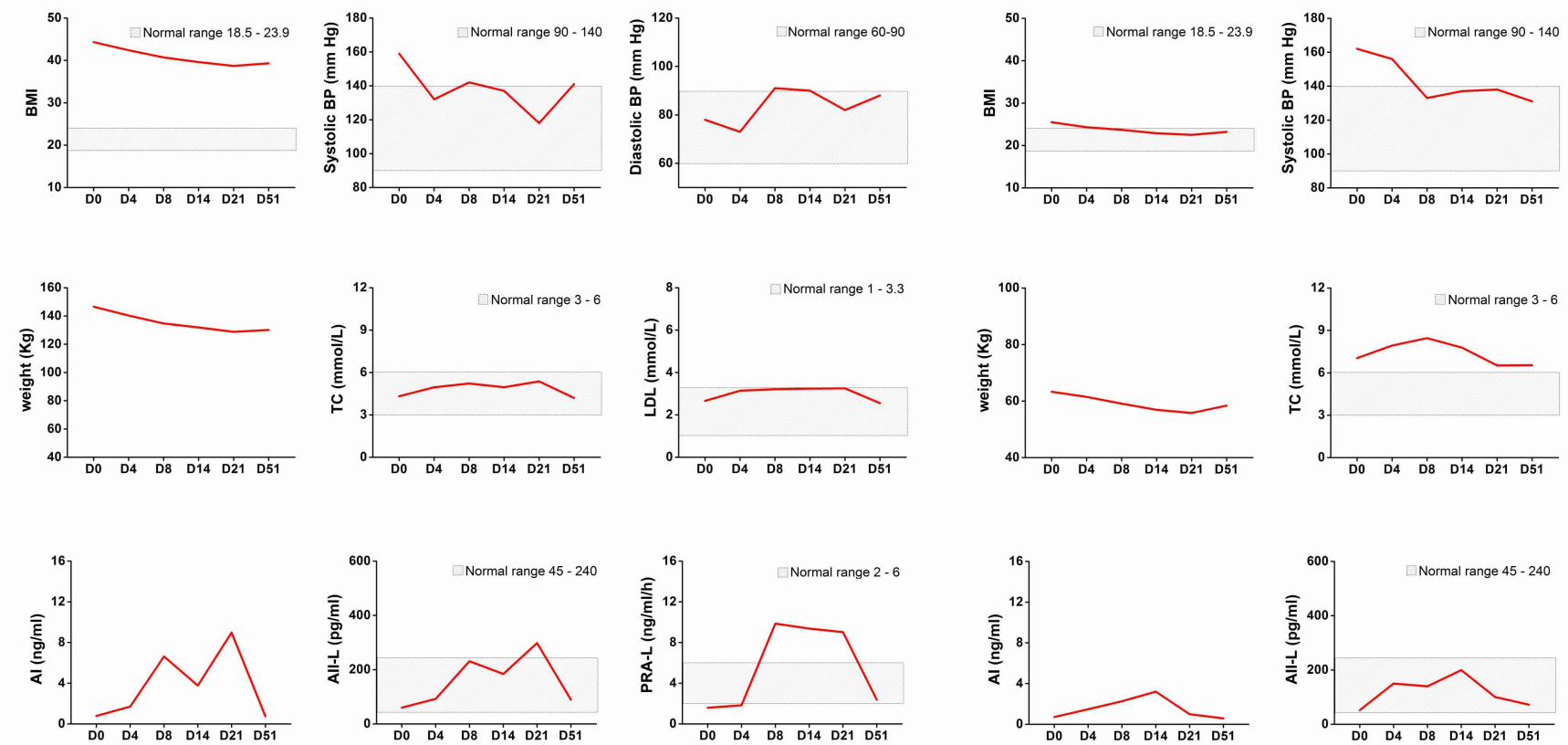
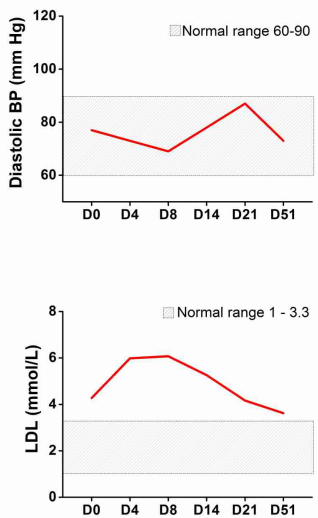

Fig. 4. Dynamics of the levels of physical biomarkers for specific cases. The data were examined at indicated time points. Dash areas show the normal ranges.

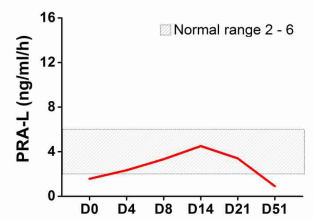




\begin{tabular}{|c|c|c|c|}
\hline & $\begin{array}{c}\text { A basic survey } \\
(n=124)\end{array}$ & $\begin{array}{l}\text { A detailed Analysis } \\
(n=53)\end{array}$ & $\begin{array}{l}\text { A prospective trial } \\
(n=20)\end{array}$ \\
\hline Median age (years) & $47 \pm 10$ & $50 \pm 10$ & $60 \pm 13$ \\
\hline$\geqq 60$ years & $14(11 \%)$ & $9(17 \%)$ & $10(50 \%)$ \\
\hline \multicolumn{4}{|l|}{ Sex } \\
\hline Female & $76(61 \%)$ & $34(64 \%)$ & $13(63 \%)$ \\
\hline Male & $48(39 \%)$ & $19(36 \%)$ & $7(37 \%)$ \\
\hline \multicolumn{4}{|l|}{ Weight (kg) } \\
\hline Baseline & $69 \pm 15$ & $73 \pm 16$ & $74 \pm 21$ \\
\hline Day 21 of bigu & $61 \pm 13$ & $62 \pm 13$ & $65 \pm 19$ \\
\hline \multicolumn{4}{|l|}{ BMI } \\
\hline Baseline & $24.7 \pm 4.5$ & $25.0 \pm 4.1$ & $26.5 \pm 5.1$ \\
\hline Day 21 of bigu & $21.8 \pm 4.0$ & $21.7 \pm 3.5$ & $23.4 \pm 4.6$ \\
\hline \multicolumn{4}{|l|}{$\mathrm{SBP}(\mathrm{mmHg})$} \\
\hline Baseline & $126 \pm 17$ & $127 \pm 19$ & $143 \pm 25$ \\
\hline Day 21 of bigu & $114 \pm 12$ & $110 \pm 12$ & $117 \pm 21$ \\
\hline \multicolumn{4}{|l|}{$\mathrm{DBP}(\mathrm{mmHg})$} \\
\hline Baseline & $82 \pm 14$ & $83 \pm 15$ & $79 \pm 12$ \\
\hline Day 21 of bigu & $74 \pm 9$ & $71 \pm 10$ & $76 \pm 11$ \\
\hline \multicolumn{4}{|c|}{ Triglycerides (mmol/L) } \\
\hline Baseline & nd & $1.8 \pm 1.4$ & $1.6 \pm 0.8$ \\
\hline Day 21 of bigu & nd & $1.3 \pm 0.5$ & $1.4 \pm 0.3$ \\
\hline \multicolumn{4}{|c|}{ Total cholesterol(mmol/L) } \\
\hline Baseline & nd & $5.9 \pm 1.3$ & $5.5 \pm 1.1$ \\
\hline Day 21 of bigu & nd & $5.0 \pm 1.2$ & $5.7 \pm 0.9$ \\
\hline \multicolumn{4}{|l|}{$\mathrm{LDL}(\mathrm{mmol} / \mathrm{L})$} \\
\hline Baseline & nd & $4.1 \pm 1.0$ & $3.3 \pm 0.7$ \\
\hline Day 21 of bigu & nd & $3.4 \pm 0.9$ & $3.5 \pm 0.6$ \\
\hline \multicolumn{4}{|l|}{ HDL (mmol/L) } \\
\hline Baseline & nd & $1.4 \pm 0.4$ & $1.3 \pm 0.2$ \\
\hline Day 21 of bigu & nd & $1.2 \pm 0.4$ & $1.1 \pm 0.1$ \\
\hline \multicolumn{4}{|l|}{ Glucose (mmol/L) } \\
\hline Baseline & nd & $5.3 \pm 2.3$ & $6.1 \pm 3.2$ \\
\hline Day 21 of bigu & nd & $4.9 \pm 2.0$ & $4.8 \pm 1.2$ \\
\hline \multicolumn{4}{|l|}{ Uric acid (mmol/L) } \\
\hline Baseline & nd & $403.0 \pm 113.4$ & $326.1 \pm 114.0$ \\
\hline Day 21 of bigu & nd & $462.6 \pm 229.8$ & $636.6 \pm 202.4$ \\
\hline \multicolumn{4}{|l|}{$\mathrm{ALT}(\mathrm{U} / \mathrm{L})$} \\
\hline Baseline & nd & $21.0 \pm 12.3$ & $21.9 \pm 14.8$ \\
\hline Day 21 of bigu & nd & $25.1 \pm 18.9$ & $34.6 \pm 43.7$ \\
\hline \multicolumn{4}{|l|}{ AST (U/L) } \\
\hline Baseline & nd & $25.9 \pm 14.1$ & $22.8 \pm 9.1$ \\
\hline Day 21 of bigu & nd & $31.7 \pm 18.2$ & $37.7 \pm 29.0$ \\
\hline \multicolumn{4}{|l|}{ BUN (mmol/L) } \\
\hline Baseline & nd & $5.7 \pm 1.4$ & $6.5 \pm 1.3$ \\
\hline Day 21 of bigu & nd & $3.6 \pm 1.2$ & $4.7 \pm 1.2$ \\
\hline
\end{tabular}

Table 1. Patient demographics, baseline characteristics and biomarker changes after bigu regimen. 


\section{Categories Bigu Normal Ratio(\%)}

Calories(KJ)

$283.58 \quad 8263.40$

3.43

Total Fat(g)

2.12

65.84

3.21

Carbohydrate(g)

10.21

320.94

3.18

Dietary Fiber(g)

0.60

25.00

2.40

Protein(g)

0.85

55.00

1.55

Vitamin A( $\mu \mathrm{g})$

Vitamin $\mathrm{C}(\mathrm{mg})$

Vitamin $\mathrm{E}(\mathrm{mg})$

$\mathrm{Na}$ (mg)

$\mathrm{Ca}(\mathrm{mg})$

$\mathrm{Fe}(\mathrm{mg})$
0.28

1.00

1.28

10.41

9.26

0.38
750.00

100.00

14.00

1450.00

900.00

14.00
0.04

1.00

9.17

0.72

1.03

2.70

Table 2. Nutrition composition during bigu regimen. 


\begin{tabular}{lcccccccc}
\hline From bigu & Day 22 & Day 23 & Day 24 & Day 25 & Day 26 & Day 27 & Day 28 & Day 29-31 \\
From resuming diet & Day 1 & Day 2 & Day 3 & Day 4 & Day 5 & Day 6 & Day 7 & Day 8 \\
\hline Calories(kcal) & 347.44 & 694.88 & 1529.75 & 2545.63 & 3610.21 & 5409.87 & 6342.90 & 8325.99 \\
& & & & & & & & \\
Total Fat(g) & 1.13 & 2.26 & 4.68 & 9.16 & 10.32 & 27.11 & 28.21 & 41.30 \\
Cabohydrate(g) & 14.47 & 28.94 & 61.27 & 109.39 & 165.41 & 228.59 & 274.29 & 342.04 \\
Protein(g) & 3.27 & 6.54 & 17.16 & 22.86 & 29.03 & 38.75 & 45.75 & 69.01 \\
\hline
\end{tabular}

Table 3. Nutrition composition during the 10-day recovery diet. 


\begin{tabular}{|c|c|c|c|c|c|}
\hline & Overweight & Hypertension & Hyperlipidemia & Hyperglycemia & Fatty Liver \\
\hline Case 1 & $\sqrt{ }$ & $\sqrt{ }$ & $\sqrt{ }$ & $\sqrt{ }$ & none \\
\hline Case 2 & $\sqrt{ }$ & & & & none \\
\hline Case 3 & $\sqrt{ }$ & & & & none \\
\hline Case 4 & $\sqrt{ }$ & $\sqrt{ }$ & $\sqrt{ }$ & & mi to mo \\
\hline Case 5 & $\sqrt{ }$ & $\sqrt{ }$ & & & none \\
\hline Case 6 & $\sqrt{ }$ & $\sqrt{ }$ & $\sqrt{ }$ & & none \\
\hline Case 7 & $\sqrt{ }$ & & $\sqrt{ }$ & & none \\
\hline Case 8 & & $\sqrt{ }$ & & & none \\
\hline Case 9 & $\sqrt{ }$ & & $\sqrt{ }$ & & moderate \\
\hline Case 10 & $\sqrt{ }$ & $\sqrt{ }$ & & & severe \\
\hline Case $11^{\S}$ & $\sqrt{ }$ & & & & moderate \\
\hline Case 12 & $\sqrt{ }$ & & & & none \\
\hline Case 13 & $\sqrt{ }$ & $\sqrt{ }$ & $\sqrt{ }$ & & mi to mo \\
\hline Case 14 & & & $\sqrt{ }$ & $\sqrt{ }$ & none \\
\hline Case 15 & $\sqrt{ }$ & $\sqrt{ }$ & $\sqrt{ }$ & & none \\
\hline Case 16 & $\sqrt{ }$ & $\sqrt{ }$ & & & mild \\
\hline Case 17 & $\sqrt{ }$ & $\sqrt{ }$ & & & severe \\
\hline Case $18^{\S}$ & & & $\sqrt{ }$ & & none \\
\hline Case 19 & $\sqrt{ }$ & $\sqrt{ }$ & & $\sqrt{ }$ & moderate \\
\hline Case 20 & & & & & mi to mo \\
\hline Total & 16 & 11 & 9 & 3 & 9 \\
\hline
\end{tabular}

Table 4. Physical examination of 20 participants before fasting procedure (day 0 ).

$\S$ indicates the withdrawn case from this clinical trial. 
Body Mass Index

Systolic Blood Pressure ( $\mathrm{mmHg}$ )

Diastolic Blood Pressure $(\mathrm{mmHg})$

Glucose (mmol/L)

Day0 Day4 Day8 Day14 Day21 Day51 Day0 Day4 Day8 Day14 Day21 Day51 Day0 Day4 Day8 Day14 Day21 Day51

\begin{tabular}{|c|c|c|c|c|c|c|c|c|c|c|c|c|c|c|c|c|c|}
\hline Day0 & Day4 & Day8 & Day14 & Day21 & Day51 & Day0 & Day4 & Day8 & Day14 & Day21 & Day51 & Day0 & Day4 & Day8 & Day14 & Day21 & Day51 \\
\hline 162 & 156 & 133 & 137 & 138 & 204 & 77 & 73 & 69 & 78 & 87 & 100 & 9.95 & 4.45 & 3.93 & 5.64 & 7.09 & 8.75 \\
\hline 120 & 108 & 114 & 99 & 92 & 121 & 69 & 55 & 64 & 64 & 64 & 75 & 5.41 & 3.44 & 3.67 & 4.08 & 4.09 & 5.36 \\
\hline 131 & 129 & 139 & 134 & 124 & 141 & 73 & 71 & 79 & 86 & 80 & 81 & 4.81 & 3.57 & 4.04 & 3.99 & 3.74 & 4.70 \\
\hline 141 & 166 & 151 & 127 & 116 & 131 & 86 & 93 & 101 & 89 & 78 & 79 & 5.18 & 3.52 & 3.65 & 4.44 & 4.44 & 5.11 \\
\hline 143 & 107 & 99 & 92 & 96 & 134 & 96 & 69 & 65 & 68 & 67 & 88 & 5.41 & 3.89 & 3.53 & 4.84 & 4.21 & 5.21 \\
\hline 185 & 150 & 138 & 138 & 131 & 179 & 104 & 83 & 90 & 85 & 86 & 103 & 5.00 & 3.09 & 3.30 & 3.07 & 4.16 & 4.98 \\
\hline 139 & 151 & 126 & 94 & 95 & 111 & 83 & 90 & 92 & 71 & 68 & 67 & 4.74 & 4.58 & 6.33 & 6.68 & 6.06 & 5.35 \\
\hline 143 & 136 & 123 & 123 & 103 & 131 & 80 & 76 & 80 & 77 & 65 & 75 & 5.04 & 2.66 & 2.74 & 3.02 & 3.48 & 4.83 \\
\hline 128 & 128 & 121 & 123 & 117 & 120 & 82 & 72 & 83 & 88 & 79 & 96 & 5.71 & 5.79 & 6.22 & 7.12 & 6.57 & 7.06 \\
\hline 159 & 132 & 142 & 137 & 118 & 141 & 78 & 73 & 91 & 90 & 82 & 88 & 4.68 & 3.53 & 4.50 & 5.48 & 5.29 & 5.60 \\
\hline 116 & 114 & wd & wd & wd & wd & 70 & 62 & wd & wd & wd & wd & 5.36 & 3.50 & wd & wd & wd & wd \\
\hline 117 & 108 & 106 & 110 & 103 & wd & 66 & 66 & 62 & 72 & 62 & wd & 5.08 & 3.20 & 4.10 & 4.20 & 4.66 & wd \\
\hline 167 & 162 & 160 & 148 & 150 & 137 & 80 & 76 & 76 & 85 & 92 & 74 & 5.58 & 3.88 & 3.50 & 4.86 & 4.51 & 6.26 \\
\hline 94 & 82 & 111 & 96 & wd & wd & 63 & 60 & 71 & 72 & wd & wd & 18.08 & 7.74 & 6.37 & 11.29 & wd & wd \\
\hline 176 & 149 & 118 & 130 & 125 & 143 & 103 & 89 & 84 & 107 & 93 & 98 & 4.65 & 3.04 & 3.49 & 5.19 & 3.48 & 5.52 \\
\hline 167 & 145 & 175 & 148 & 133 & 158 & 76 & 74 & 83 & 89 & 81 & 71 & 5.70 & 3.53 & 2.27 & 4.96 & 3.65 & 6.44 \\
\hline 154 & 147 & 151 & 164 & 164 & 160 & 69 & 71 & 78 & 80 & 83 & 70 & 3.50 & 3.73 & 4.03 & 4.63 & 5.06 & 6.19 \\
\hline 123 & 118 & 110 & 101 & 96 & 130 & 63 & 62 & 60 & 62 & 59 & 68 & 3.27 & 3.73 & 3.92 & 4.15 & 4.37 & 5.47 \\
\hline 166 & 127 & 133 & 128 & 116 & 192 & 93 & 72 & 78 & 85 & 81 & 103 & 9.56 & 6.87 & 4.78 & 6.15 & 7.27 & 12.86 \\
\hline 101 & 92 & 101 & 94 & 88 & 90 & 70 & 56 & 69 & 77 & 66 & 62 & 5.33 & 2.74 & 3.18 & 3.79 & 4.21 & 4.99 \\
\hline
\end{tabular}

\begin{tabular}{|c|c|c|c|c|c|c|c|c|c|c|c|c|c|c|c|c|c|c|c|c|c|c|c|c|}
\hline & \multicolumn{6}{|c|}{ Low Density Lipoprotein (mmol/L) } & \multicolumn{6}{|c|}{ Total Cholesterol (mmol/L) } & \multicolumn{6}{|c|}{ Triglyceride } & \multicolumn{6}{|c|}{ Fatty liver } \\
\hline & Dayo & Day4 & Day8 & Day14 & Day21 & 1 Day51 & Day0 & Day4 & Day8 & Day14 & 4 Day2 & 1 Day51 & Day0 & Day4 & Day8 & Day14 & Day21 & Day51 & Day0 & Day4 & Day8 & Day14 & Day21 & Day51 \\
\hline Case 1 & 4.27 & 5.98 & 6.07 & 5.26 & 4.16 & 3.62 & 7.04 & 7.93 & 8.45 & 7.78 & 6.52 & 6.54 & 2.15 & 1.59 & 1.69 & 1.64 & 1.62 & 2.33 & none & none & none & none & none & none \\
\hline Case 2 & 3.11 & 3.21 & 4.57 & 4.81 & 3.95 & 2.44 & 5.53 & 5.43 & 7.17 & 7.13 & 6.25 & 4.61 & 0.72 & 0.73 & 1.36 & 1.42 & 1.18 & 1.05 & none & none & none & none & none & none \\
\hline Case 3 & 2.25 & 2.82 & 2.96 & 3.18 & 2.90 & 3.27 & 3.80 & 4.51 & 4.48 & 5.00 & 4.43 & 5.54 & 0.94 & 1.10 & 1.08 & 1.30 & 1.24 & 1.39 & none & none & none & none & none & none \\
\hline Case 4 & 3.68 & 5.95 & 7.75 & 6.64 & 4.26 & 3.82 & 6.97 & 8.76 & 10.82 & 9.27 & 7.01 & 6.55 & 3.21 & 2.61 & 1.69 & 1.38 & 1.53 & 2.03 & $\mathrm{mi}$ to $\mathrm{mo}$ & $\mathrm{mi}$ to $\mathrm{mo}$ & mild & mild & mild & mild \\
\hline Case 5 & 3.10 & 3.79 & 3.59 & 3.21 & 2.58 & 3.19 & 4.78 & 5.45 & 5.62 & 4.88 & 4.16 & 4.62 & 1.64 & 1.00 & 1.13 & 1.24 & 1.31 & 1.43 & none & none & none & none & none & none \\
\hline Case 6 & 3.93 & 4.76 & 5.66 & 5.05 & 3.86 & 3.73 & 6.39 & 7.36 & 7.96 & 7.65 & 6.13 & 6.27 & 1.19 & 1.56 & 2.18 & 1.99 & 1.53 & 1.28 & none & none & none & none & none & none \\
\hline Case 7 & 3.04 & 5.13 & 6.80 & 4.62 & 3.27 & 1.84 & 5.23 & 7.25 & 8.13 & 6.76 & 4.77 & 3.15 & 2.92 & 2.31 & 2.03 & 2.44 & 2.20 & 1.51 & none & none & none & none & none & none \\
\hline Case 8 & 2.46 & 3.87 & 4.70 & 4.26 & 3.78 & 3.02 & 4.63 & 6.50 & 7.00 & 6.80 & 6.38 & 5.80 & 0.86 & 1.40 & 1.41 & 1.28 & 1.29 & 1.20 & none & none & none & none & none & none \\
\hline Case 9 & 3.52 & 4.55 & 4.58 & 3.93 & 3.20 & 3.22 & 6.11 & 6.27 & 6.49 & 6.11 & 5.21 & 5.60 & 2.22 & 1.40 & 1.37 & 1.30 & 1.38 & 2.03 & moderate & moderate & $\mathrm{mi}$ to $\mathrm{mo}$ & mild & mild & none \\
\hline Case 10 & 2.66 & 3.14 & 3.21 & 3.24 & 3.25 & 2.55 & 4.32 & 4.95 & 5.22 & 4.96 & 5.37 & 4.20 & 1.04 & 1.52 & 1.07 & 1.10 & 1.33 & 1.10 & severe & severe & mo to se & mo to se & moderate & moderate \\
\hline Case 11 & 3.58 & 4.95 & wd & wd & $w d$ & $w d$ & 5.85 & 6.50 & wd & $w d$ & wd & $w d$ & 1.57 & 1.36 & wd & wd & wd & wd & moderate & moderate & wd & wd & wd & wd \\
\hline Case 12 & 2.82 & 4.10 & 4.64 & 3.28 & 3.15 & wd & 4.59 & 6.53 & 7.01 & 4.82 & 5.54 & wd & 0.87 & 1.04 & 1.07 & 0.93 & 1.08 & wd & none & none & none & none & none & none \\
\hline Case 13 & 4.39 & 5.18 & 5.50 & 5.04 & 4.14 & 4.57 & 6.88 & 7.19 & 7.62 & 7.69 & 6.51 & 7.05 & 1.23 & 1.32 & 1.56 & 1.42 & 1.31 & 1.24 & $\mathrm{mi}$ to $\mathrm{mo}$ & $\mathrm{mi}$ to $\mathrm{mo}$ & $\mathrm{mi}$ to $\mathrm{mo}$ & mild & mild & wd \\
\hline Case 14 & 3.52 & 4.17 & 5.14 & 3.82 & wd & wd & 6.21 & 6.48 & 7.19 & 5.96 & wd & $w d$ & 3.02 & 1.69 & 1.89 & 1.51 & wd & wd & none & none & none & none & wd & wd \\
\hline Case 15 & 4.35 & 5.02 & 5.70 & 4.04 & 3.85 & 3.28 & 6.40 & 7.36 & 8.07 & 6.14 & 6.04 & 5.71 & 1.03 & 0.94 & 1.08 & 1.00 & 1.42 & 1.19 & none & none & none & none & none & none \\
\hline Case 16 & 3.10 & 4.26 & 5.33 & 4.27 & 3.24 & 3.62 & 5.16 & 6.58 & 7.78 & 6.70 & 5.63 & 6.39 & 1.14 & 1.08 & 1.34 & 1.08 & 1.27 & 0.91 & mild & mild & mild & none & none & none \\
\hline Case 17 & 3.35 & 3.75 & 3.58 & 3.28 & 3.23 & 3.28 & 5.24 & 5.69 & 5.47 & 5.36 & 5.13 & 5.22 & 1.54 & 1.63 & 1.32 & 1.36 & 1.33 & 1.22 & severe & severe & mo to se & moderate & mi to mo & mild \\
\hline Case 18 & 4.54 & 4.52 & 3.92 & 3.15 & 2.86 & 4.41 & 7.21 & 7.02 & 6.82 & 5.40 & 5.14 & 7.14 & 1.02 & 0.96 & 1.08 & 1.04 & 0.94 & 1.13 & mild & none & none & none & none & none \\
\hline Case 19 & 2.60 & 3.86 & 4.75 & 5.27 & 4.76 & 4.66 & 4.30 & 6.11 & 6.97 & 7.53 & 7.16 & 7.29 & 1.44 & 2.17 & 1.54 & 1.45 & 1.51 & 2.60 & moderate & moderate & moderate & mi to mo & mild & mild \\
\hline Case 20 & 2.31 & 2.87 & 3.25 & 3.27 & 3.00 & 2.42 & 3.96 & 4.65 & 5.85 & 5.93 & 5.08 & 3.84 & 1.54 & 1.13 & 1.80 & 1.69 & 1.71 & 1.78 & $\mathrm{mi}$ to $\mathrm{mo}$ & $\mathrm{mi}$ to mo & $\mathrm{mi}$ to $\mathrm{mo}$ & $\mathrm{mi}$ to $\mathrm{mo}$ & mi to mo & mild \\
\hline
\end{tabular}

Table 5. Changes of individual biomarkers and imaging examinations during fasting procedure. 